\title{
VALORES SIMBOLISTAS EN LA LITERATURA ESPAÑOLA DEL PRIMER TERCIO DEL SIGLO XX
}

\author{
Rafael ALARCÓN SIERRA \\ Universidad de Jaén
}

Si toda discusión sobre fenómenos literarios debe encuadrarse, no ya en su radical historicidad, sino en un contexto historiográfico determinado, elio es doblemente necesario al referimos a la literatura española del siglo XX. Todos sabemos, y no insistiré ahora sobre ello, que el carácter específico de una literatura nacional puede darse por supuesto como formación histórica o institución establecida, pero no deja de ser, por un lado, una construcción artificial, y por otro, una historia que, como todas, es irreductible a una sola visión o teoría totalizadora. Pero, además, en el caso de la literatura española del siglo $\mathrm{XX}$, su historización ha sido especialmente desafortunada.

Cada vez parece más evidente la necesidad de conformar una nueva pericdización de la literatura española del siglo XX. Son varios los aspectos a reconsiderar. Voy a centrarme en los que más directamente atañen a su primer tercio, aunque las observaciones que haga a continuación bien podrían extenderse a tođa la centuria. El diagnóstico de los males que han aquejado a este período empieza con la ficticia oposición establecida entre los marbetes modernismo y «98», en la que no me voy a detener, dado que dicho enfrentamiento ha ido desapareciendo ante análisis más rigurosos, demostrando la heterogeneidad de los términos contrapuestos, e incluso la falsificación e inoperancia de uno de los mismos, el de $\langle 98 »$, ail margen tanto del verdadero contexto ideológico y estético de principios de siglo como de las coordenadas de la modernidad europea.

En segundo lugar, la utilización del método de las generaciones literarias, cultivado por Ortega y Gasset o Julián Marías, hegemónico durante mucho tiem- 
po en la historiografía literaria española. Pese a que se le han dirigido fuertes reparos, sigue siendo de empleo habitual. El problema que plantea el uso de «generación» es la pretensión de englobar sincrónicamente a un conjunto de autores por el hecho de haber nacido en fechas próximas, lo cual no garantiza la cohesión ideológica y estética del mismo. Ello da lugar a una excesiva compartimentación dentro de la evolución literaria, donde se subrayan más las diferencias entre una generación y otra que las semejanzas, incluso mediante saltos historiográficos, en lo que en realidad es una evolución literaria continua. Esto, por no hablar del olvido de las transiciones entre las supuestas generaciones o de los autores no fácilmente encasillables en una u otra generación. El resultado es que a menudo se agrandan cambios de actitud coyunturales o de matiz.

El tercer problema de este período literario, relacionado con los dos anteriores, sobre todo con el último, es la gran fortuna crítica de las llamadas «generaciones» del «98»y del «27»; hace pocos años se celebró por todo lo alto el centenario de la primera, y la segunda goza de gran prestigio popular, crítico y editorial. Estos fenómenos de autopromoción intencionada, por parte de sendos grupos de escritores, tuvieron la capacidad de arrastrar a la propia crítica filológica, haciendo el vacío sobre el verdadero panorama literario de la época y sobre los autores que no tuvieron la fortuna de pertenecer a sus exiguas nóminas. Con ello se perdió la perspectiva de conjunto y se provocó una grave distorsión histórica, hasta el punto de introducir entre ambas una «generación» todavía más problemática, la del «14», o de olvidar todo lo que no se adscribiera a estas sucesivas «generaciones». Otra cuestión era discriminar quién pertenecía a ellas y quién no: no siempre hubo acuerdo unánime en sus nóminas. En el caso del autoproclamado «27», a ello se unió, de una parte, el fetichista prestigio cultural que las vanguardias han tenido en nuestro siglo (vanguardias que, paradójicamente, los supuestos componentes del «27» atemperaron en realidad); de otra, la reivindicación civil, política y ética de una creación partida por la guerra y, por último, la tribuna universitaria, a la que pertenecieron algunos de sus integrantes. Algo se soluciona, aunque poco, con cambiar el marbete de «generación» por el de «grupo»-o el todavía más neutro de «comunidades de edad»-. Mayor importancia ha tenido el paulatino estudio y análisis de los autores y obras no incluidos en estas selectas nóminas.

En cuarto y último lugar, otro problema ha venido por el tipo de estudio que se ha hecho de los manifiestos, proclamas y declaraciones de los propios creadores. No hará falta decir que los textos de este tipo son consustanciales a la literatura moderna, y que su análisis y estudio es, desde luego, inexcusable y muy orientador. Sin embargo, el filólogo, quizá por comodidad, a veces ha olvidado que una cosa son las intenciones teóricas y otra cosa el resultado artístico alcan- 
zado, y que pocas veces ambos aspectos se corresponden. Por ello es necesario contrastarlos siempre, y no caer en la tentación, como ha podido suceder, de dejarse guiar más por los manifiestos que por las obras artísticas, analizándolas exclusivamente en función de los anteriores. En España, como sabemos, hubo más «vanguardia» proclamada que efectiva. $Y$ un cambio estético nunca se ha podido producir a través de un manifiesto programático, por muchos apoyos que éste obtuviera por parte de los mismos creadores. Los cambios se producen a través de las obras, no de las proclamas. Y ni siquiera basta con que un conjunto de obras opten por un cambio determinado para que éste se introduzca plenamente en la corriente literaria.

Los cuatro aspectos que he destacado hasta ahora como distorsionadores de la historia literaria son claramente determinaciones microhistóricas. Y no basta con sustituirlas por otras para que todo se arregle. Por ello, debemos acudir al ámbito macrohistórico de la periodización. En este ámbito, la literatura española del siglo XX se ha estudiado tradicionalmente como una serie de sucesivos compartimentos más o menos estancos, de modo que, si el modernismo se acababa cuando entraban en escena las vanguardias y el 27 , la discusión consistía en saber en qué fecha sucedía esto; permítaseme un pequeño juego y observemos los «adelantos» cronológicos de la crítica: Juan Cano Ballesta, La poesía española entre pureza y revolución (1930-1936) -pero 1920-1936 en su segunda edición (Cano Ballesta 1972 y 1996)-; Ramón Buckley y John Crispin, Los vanguardistas españoles (1925-1935) (Buckley \& Crispin 1973); Anthony Leo Geist, La poética de la generación del 27 y las revistas literarias: de la vanguardia al compromiso (1918-1936) (Geist 1980); Juan Manuel Bonet, Diccionario de la vanguardia en España 1907-1936 (Bonet 1995). Richard Cardwell, por su parte, titulaba un artículo «Alma, de Manuel Machado [publicado en 1902], ¿primer libro de las vanguardias?» (Cardwell 1997). Por supuesto, con esta anécdota no trato de simplificar el contenido de los estudios citados, sino mostrar un síntoma de lo que pudiera parecer cierta desorientación historiográfica que en ocasiones se puede deslizar peligrosamente hacia el reduccionismo.

Para evitarlo, bueno será plantearnos el problema de la periodización atendiendo a un modelo plural o polifónico, basado en una múltiple temporalidad, tal y como nos ha enseñado, por ejemplo, Claudio Guillén (C. Guillén 1985 y 1989). El período se presenta de este modo como una interrelación de corrientes, algunas de las cuales proceden del período anterior, mientras otras siguen evolucionando hacia el futuro. El sistema literario, así entendido, se caracteriza por la continuidad de ciertos componentes, la desaparición de otros, el despertar de posibilidades olvidadas, la rápida interrupción de novedades, o el efecto retardado de 
otras. Hay grandes reputaciones que se vienen abajo -como pudo ocurix, on nuestro ámbito, con el teatro de Echegaray-, y, a la vez, una necesidad constante de revalorizar el pasado -paradigmática resulta la recuperación de Góngora en el primer tercio del siglo XX, a la que luego volveré-. Estas concepciones fexibles y múltiples de la periodización permiten que el historiador de la híeratina destaque una corriente determinada sin tener que identificarla forzosamento con todo un espacio temporal.

Lo que deberíamos descartar, por tanto, es la noción de período como concepto que aspira a coincidir en su totalidad con un segmento de tiempo dado, constituyendo así una hipotética unidad de la historia literaria que une artificiosamente continente y contenido. Muy al contrario, esta sccción de tiempo no es absoluta: dentro de dicho campo temporal surgen y perdurar corrientes y movimientos, sucesivos y paralelos, que no tienen la misma duxación, intensidad o maduración, y se establece un diálogo entre procesos prolongados y otros más breves (Guillén 1989, pág. 124). De esta forma, los conceptos que la crútica propone bajo términos como modernismo, vanguardia, joven litertura, «27», no se convierten en marbetes monolíticos y cerrados, totalizadores y excluyentes, que se suceden uno detrás de otro como compartimentos estancos, sino que pueden convivir, como de hecho sucedió, simultáneamente, con numerosos entrecruzamientos. Como sabemos, en las primeras décadas del siglo incluso convivieron normas estéticas contrapuestas y distintas corrientes o movimientos en pugna, sin que ninguno de ellos pudiera reemplazar por completo a los restantes: de este eciecticismo inestable se beneficiaron los más brillantes autores tanto del modernismo como de la «joven literatura» de los años veinte y treinta, y seguramente este es uno de los factores que contribuyeron a la excelencia artística y litekaria deiperíodo.

Deber̂́amos considerar los fenómenos que intervienen en la evoícín literaria desde la perspectiva de la «duración», en el sentido que le otorga temand Braudei cuando distingue entre larga, media y corta duración (Braudel 1968). Es evidente que buena parte de los problemas en la literatura española del siglo $X X$ se han originado por haber atendido preferentemente a los fenómenos cie corta duración, en detrimento de los de larga o media. Ello ha sido así, en parte por los métodos de análisis tradicionales en nuestra filología, y en parte por no haber tenido ia suficiente perspectiva de conjunto para ofrecer una sistematización que hoy, al menos para la primera parte del siglo, sí estamos en condiciones de construir. Pero aún diré más: mientras que fenómenos literarios como las generaciones o grupos autoconstituidos, los manifiestos y proclamas, e incluso los bróes vanguardistas, sobre todo en España, pertenecen sin duda al ámbito de la corta 
duración, el simbolismo (no como escuela, claro está, sino considerando los valores estéticos e ideológicos que introduce), hoy estamos en condición de afirmarlo con la necesaria visión crítica y distancia temporal, sí se ha demostrado como un fenómeno de intermedia e incluso de larga duración. Y no sólo eso, sino que, además, fue uno de los que originaron el verdadero cambio de sistema en la literatura española a finales del siglo XIX y comienzos del XX, y, desde luego, el sustrato común de los escritores del primer tercio de este siglo. Cada vez parece más clara la tendencia que tiende a interpretar toda la poesía que va desde el modernismo hasta la llamada (provisionalmente) postmodernidad-inciúda la aparente ruptura vanguardista- como una corriente que comparte unos preszipuestos básicos, aun distinguiendo diversas fases o variedades internas. Para entendernos: entre un buen poeta del siglo XIX y un buen poeta modernista existe una quiebra importante: la del cambio de sistema que se va produciendo en el último cuarto del siglo XIX. Pero, ¿ocurre lo mismo entre un buen poeta modernista y otro de la «joven literatura» de los años veinte? Entre ambos habrán cambiado algunas normas estéticas, pero no parece que haya cambiado el sistema literario. Bien lo señalaron tanto Antonio Machado como Juan Ramón Jiménez en sus escritos teóricos -pese a que reconozcamos la posición interesada de ambos-, quienes no veían en los autores más jóvenes sino la herencia del simbolismo, lo cual para el primero merecía una consideración negativa, que era positiva para el segundo'. Quizá no se ha insistido lo suficiente en la importancia crucial que los valores simbolistas cobran tras ser pasados por el filtro de la vanguardia, relectura que explica en buena medida los logros de la poesía española del siglo XX, y particularmente los de su primer tercio. Eso es lo que hace, precisamente, que la importante obra de Juan Ramón Jiménez evolucionara fiuidamente en el sentido que todos conocemos, vertebrando la poesía del siglo $\mathrm{XX}$ sin abandonar sus presupuestos simbolistas, o que muchos autores, de Ramón Gómez de la Serna a Federico García Lorca, tuvieran un aprendizaje en el modernismo, y que posteriormente evolucionaran, sin complejos ni traumas, hacia cauces expresivos más abiertos (Alarcón Sierra 2000b). Por supuesto, también puede ocurrir que poetas que pertenezcan a distintos sistemas literarios puedan compartir aigunas normas estéticas: para que cambie un sistema no es necesario que se transformen todas las normas y al contrario, pueden cambiar normas sin que por ello cambie el sistema.

' Antonio Machado lo apunta a partir de los años veinte, especialmente en «Reflexiones sobre la lírica» o en su proyecto de discurso de ingreso en la Academia Española, que he analizado en $R$. Alarcón Sierra, «Las prosas dispersas de Antonio Machado (1893-1936)», en A. Machado, Prosas dispersas (1893-1936), Madrid, Páginas de Espuma, 2001, págs. 50-76. J. R. Jiménez lo señala en muy distintos escritos a lo largo de su vida, aunque su posición quizá pueda sintetizarse en los apuntes del curso sobre El modernismo. 
Tras estos prolegómenos historiográficos, todo resulta más sencillo si acudimos a las primeras décadas del siglo: son los mismos escritores los que se saben inmersos en una crisis que afecta a los fundamentos de toda la cultura occidental -racionalismo, progreso, positivismo, materialismo, cientifismo-, y así lo declaran. Por ende, todos ellos tienen un legado común: la presencia de Schopenhauer y Nietzsche, verdaderos educadores intelectuales del momento en toda Europa, y el sustrato de la estética simbolista en sentido amplio, que se refleja en Antonio Machado o Valle-Inclán no menos que en Azorín o Baroja, (o, posteriormente, en García Lorca o Jorge Guillén). Todos ellos expresaban rechazo de la sociedad burguesa y afanes de renovación, y todos ellos eran denominados de la misma manera: la «gente nueva», los «nuevos», los «novadores», los «modernistas» o los «novísimos». Lo importante es que desde el fin de siglo se produce el intento de sincronizar la literatura española con las letras europeas, el anhelo de ser moderno, de estar a la última. Si estos autores son valiosos no es por su proximidad a la pérdida de los restos de un imperio colonial, ni por sus supuestas jeremíadas, ni por el nacionalismo decimonónico, herderiano y positivista de unos cuantos. Lo auténticamente valioso de estos escritores es que en sus obras germinan y se problematizan estéticamente muchos aspectos de una verdadera modernidad (Alarcón Sierra 1998).

La escritura finisecular en España, como en toda Europa, supone una crisis de la cultura occidental y un cuestionamiento que alcanza todos los niveles, y su reflejo estético en los escritores modernistas y de la mal llamada «generación del 98» es la verdadera herencia que reciben los jóvenes poetas de las décadas siguientes. Un legado que supone en todos los ámbitos de la literatura, pero especialmente en la lírica, el establecimiento de unos presupuestos que fundamentan su producción. Esto lo sabían los propios creadores, aunque posteriormente, la historiografía generacional, la marginación del genuino significado del modernismo y la gran fortuna crítica del «27», hayan oscurecido y fragmentado el proceso dialéctico en la evolución natural de la lírica en las primeras décadas del siglo.

Haré cuatro catas bien significativas que muestran esta continuidad y que nos harán reflexionar. Gerardo Diego, en su reseña de la Segunda antolojía poética de Juan Ramón Jiménez en 1923, apunta: «es sólo con nuestros días, que nuestros poetas se proponen horizontes más despegados, cuando, ya que no el logro ambicioso de sus aspiraciones, consiguen, por añadidura, por superación, las más absolutas calidades simbolistas» (Diego 1923, pág. 366). Jorge Guillén, al ocuparse en 1924 de las Nuevas canciones de Antonio Machado, declara: «El verso va derecho al silencio, a la soledad; si es posible, sin romperlos ni man- 
charlos. Tal ha sido el propósito, la voluntad manifiesta de los maestros, del simbolismo acá. El resultado ahora lo estamos viviendo: la poesía ha dejado de ser un arte social; al público no le interesan los poetas; los poetas se vuelven de espaldas al público» (J. Guillén 1980, pág. 394). Pedro Salinas, al preguntarse en 1940 por «El signo de la literatura española del siglo $\mathrm{XX}$ » $\mathrm{y}$ centrarlo en un «lirismo básico, esencial», «del espíritu», establece una continuidad en la «altura y densidad de la producción poética desde 1900 hasta hoy», constante presencia de la «poesía española moderna» con un «desarrollo ondulatorio de 1900 a 1940» que «se continúa, pero no se repite; es fiel a sí misma, sin imitarse» (Salinas 1970, págs. 34-40). Finalmente, Dámaso Alonso escribe tajantemente: «desde fines del siglo pasado hasta la generación de que hablamos [la de «1927»] no hay ninguna discontinuidad, ningún rompimiento esencial en la tradición poética. Puedo decir más: no hay quiebra fundamental alguna (por muy distintos que sean los extremos) entre la revolución modernista y la poesía de hoy [...] Entre el modernismo y el momento de los Machado y Juan Ramón Jiménez, entre éstos y mi generación, entre mi generación y los poetas jóvenes de ahora, el cambio, en cada caso, se señala por quiebras más o menos superficiales, pero hay un tejido continuo por debajo y muchos elementos que sirven de laña o ensambladura. Nunca, un desgarrón definitivo. ¡Nunca, una protesta fundamental contra lo inmediatamente anterior!» (Alonso 1958, págs. 167-192)2.

¿Cuáles son los fundamentos poéticos de esta continuidad? Estos presupuestos, compartidos tanto por los escritores modernistas como por los poetas de las siguientes décadas, incluidos los agrupados en el llamado grupo del « $27 »$, tienen una base en gran parte simbolista y, simultáneamente, un cuestionamiento de esta misma base que posibilita su propio carácter dinámico y abierto. La historia de la poesía en el siglo XX es, en buena medida, la historia de las diversas maneras de enfrentarse al problema de elegir entre pureza y vida en la creación artística, de cómo relacionarlas -convertir el arte en vida o la vida en arte-, sus tentativas y soluciones diversas: del simbolismo puro de Mallarmé a la reacción humana de Verlaine, los unanimistas, los humanistas, etc.; del modernismo idealista al más prosaísta, o de lo individual a lo social: es el camino que va de las Soledades a Campos de Castilla en Antonio Machado, o de Alma a El mal poema en su hermano Manuel. Parecida será la senda que lleva de la intelectualizada «poesía pura» a la posterior «rehumanización neorromántica».

${ }^{2}$ Cf. además Francisco Ayala, Reflexiones sobre la estructura narrativa, Madrid, Taurus, 1970, págs. 8-9: «En la época de mi juventud prevalecía la tendencia, iniciada ya en el simbolismo trancés, cultivada por el modernismo y llevada por la vanguardia hasta su último extremo, a desnudar el poema de cualquier ingrediente ajeno a su propósito artístico, eliminando de él toda 'literatura'». 
Siguiendo un proceso común a toda la poesía occidental, los modernistas -con el precedente de Bécquer, una y otra vez recordado por Juan Ramón Jiménez (Jiménez 1999, págs. 12-13, 20, 32, 43, 69, 84, 93, 95, 165 6́ 177)- hicieron silyos los procedimientos simbolistas, y los autores del «27» no harán sino depurarlos, quintaesenciarlos y profundizar en ellos como base fundamental de su poética $a^{3}$. Lá tradición simbolista europea, que los modernistas españoles enriqueceñ, alcanza sa apogeo años después, y fructifica en poetas como Rilke, Valéry, Saint Joh Perse, Eliot, Wallace Stevens, Yeats, García Lorca o Salvatore Quasimodo, como ya señalaron hace tiempo desde Edmund Wilson (Wilson 1977) hasta Anna Balakian (Balakian 1969 y 1982). Pero, incluso en la segunda mitad del siglo $\mathrm{XX}$, los valores simbolistas dejan su huella, aunque ya con otro significado y entremezciados con otros elementos: no hará falta hacer recuento de cuántos poetas españoles del siglo XX han reconocido el magisterio efectivo que sobre ellos ejerció Rubén Darío, Juan Ramón Jiménez o Antonio Machado. La mayoría de las corrientes poéticas que se han desarrollado en España desde 1936 siguen manteniendo vínculos con la tradición simbolista, incluso en el concepto de poema. Y no hará falta resaltar el neosimbolismo de los novísimos, el modernismo en tono menor de tantos poetas de los 80 y los 90 , o el fenómeno de los nietos declarados de Manuel Machado, siguiendo una recuperación ya iniciada por Jaime Gil de Biedma.

La crisis de la modernidad traerá consigo la pérdida de una imagen y un sentido armónico del universo y de la vida; la pérdida de confianza en la civilización occidental, en el progreso y en la linealidad histórica; el abandono y aislamiento definitivo del artista en el sistema de mercado y el simultáneo rechazo y atracción hacia la clase social a la que pertenece y de la que depende. Todo ello conformará las bases de la creación contemporánea según unos fundamentos que, aunque sugeridos e incluso enunciados ya en el romanticismo alemán, no tendrán en muchos casos un pleno y coherente desarrollo artístico hasta llegar al simbolismo, de Baudelaire en adelante, y, en el ámbito hispánico, al modernismo. El arte será entendido entonces como la actividad antimimética, autónoma y autotélica de un creador autoconsciente; un vitalismo esteticista, individualista, hermético e intrasubjetivo, lleno de tensiones en un horizonte de profundo nihilismo, escepticismo y desconfianza -fragmentación y escisión del mundo, el yo, la vida, el tiempo y el lenguaje-que paradójicamente oscilará entre lo trascendente y lo intrascendente; entre su tentativa de una vida más pura y el odio hacia la vida;

"A demostrar que los modernistas y los jóvenes del «27» comparten una misma concepción del poema como «icono» o reservorio de una experiencia se ha aplicado Andrew Debicki en Historia de la poesía española del siglo XX. De la modernidad hasta el presente, Madrid, Gredos, 1997. 
entre su refugio en el arte y su odio hacia la cultura; entre su empleo de la razón y el intelecto y su tentativa de derrotar a ambos; entre sus especializados procedimientos y técnicas artísticas y el efecto de sugerencia y misterio buscado; entre su individualismo y la disolución del yo; entre la consagración del arte como la nueva religión y a la vez la autoconciencia del fracaso úitimo de toda tentativa estética; entre su visión amoral, su indignación moral y su búsqueda de una perfección ética y estética. En definitiva, entre la búsqueda de un significado y la sospecha en la posible ausencia de éste.

En tanto que creadores y críticos -esferas ya siempre unidas en ia modernidad-, con ei precedente teórico de los románticos alemanes, tras Poe y Baudeiaire es sobre todo Mallarmé quien fundamenta buena parte de los postulados simbolistas básicos en la poesía del siglo XX, y que compartirán los modernistas y los poetas de las siguientes décadas: la irreductibilidad y la autorreferencialidad de la experiencia artística. La victoria de una estética antimimética e irracionalista. La importancia de la imagen y la experimentación verbal. La alta misión del poeta como desentrañador del misterio inefable del hombre y el universo, y de la poesía como medio y fin artístico supremo para expresar la experiencia y el resultado de dicha búsqueda. La poesía como expresión suprema del misterio de la existencia, cuya misión es evocar y sugerir, mediante el ritmo y la analogía esencial de la palabra hecha símbolo, este enigma. El poema como forma perdurable que congela la experiencia de este proceso. El desarreglo de todos lo sentidos -reflejado en la sinestesia, la correspondencia o el símbolo- como medio para ilegar a lo desconocido. Las analogías entre mundo y poeta, entre los objetos y su abstracción intelectual, no suponen un sistema fijo, sino una relación dinámica, ambigua y huidiza, que constantemente cambia de contexto y significado. En paralelo con todo ello, su colofón será la interrelación y correspondencia de todas las artes, ya apuntada por el romanticismo; en el simbolismo, con su idea del arte total, literatura, música y artes plásticas evolucionarán profundamente unidas y ya no se podrán entender por separado. Ya conocemos la importancia de este proceso para las vanguardias, desde la primera relación de Apollinaire con los cubistas. En el modernismo hay una amplia colaboración entre escritores y pintores: así, por ejemplo, los casos de Valle-Inclán y Julio Romero de Torres, Picasso en la revista Arte Joven o Juan Gris haciendo la cubierta y el ex-libris de Alma. Museo. Los Cantares de Manuel Machado, por no hablar del redescubrimiento de Velázquez, Goya o el Greco a cargo de los jóvenes modernistas.

Importantísima será también la preponderancia de la ideología artística musical en tanto que manifestación intuitiva, directa e inefable del fondo del alma, tal como propondrán Verlaine o Darío, pero también Juan Ramón Jiménez, 
Valéry, Huidobro o Gerardo Diego: intentar que la poesía tenga una expresión análoga a la música; que, como ella, se origine directamente en el interior del alma y a ella se dirija. Es un proceso que, iniciado en el romanticismo (Schiller), tras Poe alcanza los vértices de su fundamentación en el triángulo formado por Schopenhauer, Wagner y Nietzsche, que establecen dicha correspondencia entre música, naturaleza y alma, vertebradora de todo el pensamiento y la estética simbolista (Hertz 1987; Alarcón Sierra 1997). La unión de música y palabra en una entidad artística superior, que sea reflejo del ritmo interior de universo y alma, también será el ideal poético modernista. Esta concepción no sólo alcanza al presupuesto básico de la flexibilidad rítmica del verso en todas sus medidas posibles, sino también a la tentativa de hacer del poema una inefable e irracional forma pura musical. La vanguardia y los poetas posteriores reformularán y actualizarán estos presupuestos, al margen de su primitiva mística. Para Gerardo Diego, por ejemplo, quien insistirá de modo constante en esta relación, una perfecta imagen múltiple será precisamente la música (Diego 1919, 1926, 1927).

En el simbolismo y el más auténtico modernismo, junto al ideal de un absoluto imposible -el distanciamiento entre lenguaje y experiencia, la imposibilidad de «decir»- y su consiguiente vivencia de fracaso -el hastío existencial, la angustia del vacío, la pulsión de muerte, la petrificación solipsista o el silencio de la nada-, también aparece el juego y el placer de la escritura relacionado con la dimensión no referencial de la poesía y con la inmanencia material y espiritual de la forma, una exaltación lúdica, erótica e incluso frívola y mundana. Junto al dolor y la impotencia aparece también el gozo, la libertad dinámica del azar y el juego. Junto a la poesía como sustitución y transformación de la realidad en su dialéctica de presencias y ausencias con el yo, aparece también una función festiva y gratuita, tanto una liturgia que se celebra a sí misma como una fiesta para el intelecto -aspecto que prolongarán Valéry y los poetas de los años veinte: la escritura, territorio de la duda, es un juego verbal y sirve para un juego (Mallarmé, «La Musique et les Lettres»), pero un juego bellamente insensato y desesperado, que compromete la vida y la muerte. Por ende, ello exigirá un nuevo lector especializado, que es invitado al juego de leer, recrear e interpretar activamente el poema, de descubrir «la jouissance du poème qui est faite du bonheur de deviner peu à peu» (ibid.). Este juego verbal también tendrá otro reverso: su gratuidad e irracionalidad será el arma de la rebelión contra la sociedad y el arte establecidos, una manera de «épater», de escandalizar y de atacar las convenciones, tanto en Baudelaire como en Lautréamont, Rimbaud, Jarry o en el simbolismo y el modernismo de modo general. Será una manera de no entrar en el círculo de la praxis vital, de los valores positivistas, mercantilistas, «utilitarios» de la época, y, simul- 
táneamente, de crear un subversivo entrecruzamiento a la vez lúdico y serio de arte y vida al margen de la sociedad burguesa.

Estos valores no son, por tanto, exclusivos de la vanguardia, ni siquiera de la más radical. Como botón de muestra, recordaré un solo caso, bien documentado: Reinhard Döhl ya puso de manifiesto que Hugo Ball eligió en 1915 el nombre de Cabaret Voltaire con la intención de asociar a dadá con el Café de Voltaire de París donde Mallarmé y los simbolistas se reunían hacia 1890, pues lo que pretendían poner en práctica Ball y sus socios no era otra cosa que el programa mallarmeano de purificación lingüística y expresión privada. Incluso el fundamental concepto de «capricho del azar» aplicado al lenguaje no sólo remite a Igitur de Mallarmé, sino a la «poesía en trance» ensayada por los simbolistas hacia 1890 (Döhl 1967, pág. 36; Steiner 1980, pág. 224). El ejemplo me vale para insistir en el enriquecimiento que la vanguardia supone para los valores simbolistas más productivos, cuya relectura dota de un nuevo impulso.

Por parte de autores como Verlaine -parcialmente- y sobre todo Corbière o Laforgue, o Manuel Machado, Valle-Inclán y Ramón Gómez de la Serna, se practicará otro tipo de escritura simbolista, un confesionalismo antirromántico y «anticonfesional», que emplea el coloquialismo, el prosaísmo, la trivialidad, lo cotidiano, la ironía, el histrionismo, la bufonería, la burla y la negación nihilista de sí mismo, de su alienación y de su malestar, junto a un tono naîf, unos ritmos dislocados y juguetones, y un ingenio cómico de agudeza y «chispa» verbal. La desconfianza en la palabra hace que sean la autoironía, la intrascendencia del juego y la conciencia del simulacro los que otorguen paradójico valor a la poesía. Ello supone una poderosa carga de profundidad: la destrucción tanto del «elevado» lenguaje lírico como de su propio personaje poético, exponiendo en el poema una no-identidad, una falta de identidad y de significado que gira constantemente en el vacío de sí misma.

Coincidiendo en el tiempo con las investigaciones de Freud, Bergson o Hartmann, el poeta se quita su máscara y tras ella descubre que no hay nada. Es, por ejemplo, lo que hace Manuel Machado consigo mismo en El mal poema. En todos los casos, paradójicamente surge una obra donde toda la composición es subjetividad, un puro yo; una vez que la caída de máscaras simbolista ha anulado el sujeto lírico convencional, distanciado de sí mismo, astillado en un juego de espejos, desintegrado en su propia contradicción, el sujeto se transforma en el objeto de su propia creación mediante una constante autorreflexividad, una conciencia profunda de sí mismo a través de los objetos. La desaparición del yo en el simbolismo, a través de los estados de alma proyectados en paisajes y objetos, de la ensoñación, lo onírico, lo subconsciente o lo alógico, se ensanchará paula- 
tinamente en la escritura de todo el siglo XX. Pero paradójicamente, también se producirá la eclosión de un nuevo sujeto lírico problemático, de carácter equívoco, simultáneamente amargado y descreído, cínico y sinvergüenza, aristócrata y bohemio, vidente e histrión, actor y espectador de su propio personaje, hecho de mil máscaras y contradicciones, que adoptará todos los papeles y toda las situaciones, pasando del patetismo al ridículo sin solución de continuidad (Alarcón Sierra, 2000a).

Este nuevo sujeto contradictorio se desarrollará en un nuevo contexto de contradicciones: la ciudad, dominio que el simbolismo traspasará a toda la poesía del siglo XX como una tentativa de objeto trascendental, un campo de experiencia abierto que, paradójicamente, funcionará antitrascendentalmente en su relación con el artista. El dominio urbano, ya en el modernismo, será el marco apropiado para desarrollar la psicología aislada y dividida del poeta, su intelectualismo defensivo, introspectivo, y el ritmo de su vida y conciencia interior frente a los ritmos del progreso y de la multitud, que finalmente hará suyos la vanguardia, aunque con los antecedentes de poetas de estirpe simbolista como Verhaeren o Romains, y por las primeras tentativas modernistas, paulatinamente entreveradas de elementos «vanguardistas» en las primeras décadas del siglo, pero con numerosas pervivencias simbolistas y finiseculares (Alarcón Sierra 1999a).

Presupuesto de desarrollo simbolista fundamental en toda la poesía moderna del siglo XX es la tentativa de superar las categorías de tiempo y espacio. Ya Baudelaire entiende la obra de arte como signo de intersección entre lo auténtico y lo efímero, fugaz conexión entre lo eterno y lo actual que detiene el flujo regular del tiempo al romper su normalidad. Nietzsche - profeta de la modernidad, tanto del fin de siglo como de la vanguardia (Foster 1981)- sitúa en el choque de lo súbito, lo imprevisible y lo sorprendente, la disolución de los esquemas perceptivos de tiempo, espacio y consciencia, vivencia del instante que supone el ámbito de la apariencia estética como gozosa superficie. Estas ideas tendrán su reflejo lírico simbolista. Tanto los modernistas como los poetas posteriores tendrán una concepción del poema como presentización intuitiva de un instante de eternidad mediante un simultaneísmo de recuerdo y experiencia, que produce un estar fuera de sí donde, paradójicamente, ya no hay conciencia de durée: de forma alógica, la amplificación de ésta hace que el tiempo se densifique, se vuelva estático y se derrame en el espacio. La experiencia de un tiempo anulado comporta la disolución del transcurso histórico; ello significa la vivencia de un instante de eternidad, en el cual la duración revierte en extensión: la de un ilimitado territorio mental donde lo otrora sucesivo es ahora simultáneo. Ello muchas veces se consigue a través del símbolo o la imagen. Incluso Valéry considerará el sím- 
bolo como «una máquina para explorar el tiempo». Este simultaneísmo de recuerdo y experiencia en un instante de eternidad supone la fragmentación y distorsión del tiempo, el espacio y la conciencia, y encuentra su reflejo en casi toda la literatura desarrollada en el siglo XX, bien mediante una morosa intensidad de percepción repetitiva y circular, bien mediante la yuxtaposición súbita y el montaje de dispersos elementos heterogéneos, bien mediante el juego, el disparate, el humor y el absurdo, o bien mediante la creación de irracionales mundos oníricos. Los ejemplos son constantes y distintas las maneras de conseguir un efecto análogo: desde Verlaine a Gide, Proust o Joyce; desde «Vísperas» de Manuel Machado a «Hora inmensa» de Juan Ramón Jiménez o «Las doce en el reloj» de Jorge Guillén.

Esta exaltación del instante provoca que la superficie de las formas y los objetos resalten con toda su aura fuera del tiempo y del espacio; la salvación a través de las cosas, en palabras ramonianas y orteguianas, tan típica de la vanguardia, la nueva manera de particularizar los objetos como forma de destacarlos en la era de la reproductibilidad mecánica, es un proceso que se inicia también en el simbolismo, con el valioso precedente de Edgar Allan Poe. Las cosas adquieren una nueva presencia esencial, un valor de fetiche, y se destaca la irradiación de su alma en todo el simbolismo y el modernismo. Los objetos suntuarios, pero también los enseres cotidianos, se adueñan de la vida y de las artes. La vanguardia y la «joven poesía» de los años veinte esencializará esta actitud, la desprenderá de panteísmos espirituales y la objetivizará todavía más.

La progresiva disolución del tiempo, el espacio, la conciencia y el yo en el simbolismo tendrán su correspondiente reflejo en el lenguaje y las formas, que se convertirá en el territorio de la experimentación por excelencia. La poesía del siglo XX, por lo general, no hará sino insistir y profundizar en las innovaciones técnicas fundadas por el simbolismo, quien convierte al lenguaje en un medio hermético, opaco, autónomo, para iniciados, algo que remite a sí mismo y reflexiona sobre sí mismo. El simbolismo y el modernismo producen tanto la máxima complicación técnica y la estetización del lenguaje, su consagración a través de la metáfora, el símbolo o la imagen, como la destrucción de todas las convenciones; tanto el alejamiento del habla habitual como la identificación prosaica y conversacional con éste; tanto el cultivo especializado de las formas como su difuminación: verso libre, poema en prosa, prosa lírica, novela poemática... Cada vez más elíptico, comenzará a practicar con la yuxtaposición de elementos no estrictamente causales y hasta con las disposiciones tipográficas posteriormente características de los movimientos de vanguardia.

El modernismo destacará la renovación formal como lo más característico de la nueva revolución estética: «la modernidad supone ante todo investigar sobre 
la articulación de la realidad con las formas» (Salaün 1991, pág. 180): «los materiales y los códigos específicos de cada modo de expresión se convierten a la vez, de modo dialéctico, en sujeto y objeto» estético: «medio de expresión» y «lugar mismo de la creación»; la conclusión es que «Los lenguajes y los metalenguajes son en adelante los fundamentos de la identidad artística» (pág. 181). Este proceso se desarrolla en España con el modernismo, y es una innovación decisiva. Esta ruptura con el arte tradicional a favor de una nueva concepción estética, que destaca cada vez más el significante, las formas, la materialidad del lenguaje, es parte de la verdadera revolución artística del siglo XX, y uno de los elementos que supuso el cambio de sistema.

El simbolismo y el modernismo dan un gran paso también en la recuperación de lo popular y lo primitivo. La recreación estilizada y popularista del folklore, la leyenda tradicional, el romancero, la canción y la balada es un proceso que, iniciado en el romanticismo y en España adensado con la impronta becqueriana, adquirirá nueva resonancia en el fin de siglo. Los principales poetas modernistas, Juan Ramón Jiménez, los Machado, pero también muchos otros, iniciarán una asimilación de las formas poéticas populares, no ya con afán de glosa o calco, sino de alcanzar una expresión original a través de lo que es entendido como más auténtico y hondo, vía que continuarán los poetas del llamado «27». De la misma manera -como ya adelantó Juan Ramón Jiménez (Jiménez 1999, págs. 165 y 173-175) - muestra su continuidad el fundamento krausista, idealista, laico y liberal de buena parte de la renovación cultural española, desde la Institución Libre de Enseñanza, que dejó su huella en los Machado o Juan Ramón, hasta una filial de la anterior, la Residencia de Estudiantes, que acogerá al grupo formado por Lorca, Dalí y Buñuel y pondrá en contacto a los creadores del momento.

Precisamente, José-Carlos Mainer ha señalado cómo la reconciliación con la literatura española del pasado y el proyecto de nacionalización y modernización provino en gran medida de la tradición liberal krausista, en una construcción que abarca sin cortes desde 1900 hasta 1936 (Mainer 1981, 1989 y 1994). En el modernismo se intensifica esta recuperación de la literatura de siglos anteriores: Lope de Vega, Fray Luis de León, San Juan de la Cruz y los principales místicos españoles. Recordemos los influyentes ensayos de Unamuno o Azorín, la cantidad de obras que produjo el tricentenario del Quijote en 1905, o las adaptaciones del teatro clásico de los hermanos Machado -Tirso de Molina, Calderón y Lope de Vega-4, ejer-

4 Carlos Blanco Aguinaga, «Poéticas del 98, poéticas del 27», en M. Smerdou Altolaguirre (coord.), Ecos de la generación del 98 en la del 27, Madrid, Sociedad Estatal Lisboa 98, 1998, págs. 54-58, recuerda el rechazo de Unamuno y el Antonio Machado de Juan de Mairena al barroco de 
cicio modernizador y pedagógico en torno al drama áureo no lejano de las aspiraciones de Cipriano Rivas Cherif o Federico García Lorca. Y, paralelo a todo ello, la escuela filológica de Ramón Menéndez Pidal, coetáneo de los anteriores y de ideas análogas acerca de la literatura nacional. Los profesores formados por éste en el Centro de Estudios Históricos y los nuevos creadores prolongarán conjuntamente este proyecto sin solución de continuidad. Este contexto de interprofesionalidad (recordemos a los llamados «poetas-profesores») y nacionalismo literario celebró sucesivamente los centenarios de Góngora en 1927, de Lope en 1935 y del romanticismo, Bécquer y Garcilaso en 1936, «dando en cada momento la temperatura -creacionista, populista, neosentimental, neoclásica- de momentos que fueron, a la vez, eruditos y creadores. [...] Sin la conversión de la historia literaria española en sustancia viva del país de ayer y hoy -confluencia de lo personal y lo tradicional en la obra literaria-, tal orientación hubiera sido impensable» (Mainer 1981, págs. 469-470).

El caso más llamativo quizá sea el de Góngora, puesto que sabemos que fue el que dio nombre a la afortunada «generación del 27». Pero a Góngora no lo descubre este grupo de poetas. Ya Laurent Tailhade había escrito que «Les symbolistes [...] sont exactment ce qu'on été [...] en Espagne les gongoristes» (en Jules Huret 1891, pág. 330), y un tópico frecuentísimo acusaba a los modernistas de ser «hijos degenerados de Góngora» (Fray Candil [Emilio Bobadilla] 1903, pág. 10), de que la principal característica de los nuevos poetas era su dificultad, su «gongorismo revenant» (Díaz Gayo 1902, pág. 2), y su obra una «jerga soberana / que es Góngora vestido a la francesa» (Emilio Ferrari en su soneto satírico «Receta para un nuevo arte»). El propio Manuel Machado había calificado en 1901 La copa del rey de Thule de Villaespesa como «Gongorismo... ultra poesía» (M. Machado 1901).

Aunque aún está por hacer la historia de la importancia del vate cordobés en la literatura finisecular, lo cierto es que su prestigio no dejó de aumentar desde que se supo que Verlaine -al igual que Rémy de Gourmont- lo tenía por uno de sus autores favoritos -lo que era más pose que verdadero conocimiento, dadas sus precarias nociones del español. En España, Clarín se adelantó a esta recuperación presentando en sus ensayos críticos al autor de Soledades como la culminación de la poesía española y declarándolo entre los clásicos «el mayor de todos» («Clarín»1892, pág. 319; y 1894, pág. 120). Manuel Reina dedicó un poema a

Calderón. En esto coinciden ambos con la visión de la literatura española de la historiografía dieciochesca. Sin embargo, en el caso de Machado, habría que matizar y completar el panorama con sus artículos de reflexión teatral, que he estudiado en la introducción a la edición de A. Machado, Prosas dispersas (1893-1936), cit., págs. 76-84. 
«Góngora» en El jardín de los poetas (1899), y en el mismo año Rubén Darío hacía protagonista a éste, junto a Velázquez, de su «Trébol» de sonetos. Antonio de Zayas, por su parte, incluyó a «Góngora» entre los lienzos de Velázquez representados en sus Retratos antiguos (1902). Desde entonces será habitual encontrar artículos y debates en torno al creador del Polifemo en revistas a la última como, por ejemplo, Helios -que ya en su primer número convocó un homenaje a Góngora-, e incluso algunos poemas suyos, sobre todo romances. Juan Ramón Jiménez, que encabezó varios poemas con versos de Góngora ${ }^{5}$, había dicho que las Soledades de Antonio Machado tenían «el bello ritmo, rico y diamantino de los romances de Góngora» (Jiménez 1969, pág. 513), y posteriormente recordaría que en 1900 «rejían los simbolistas franceses y Góngora» (Jiménez 1936); Valle-Inclán alababa «el ritmo oculto de los romances antiguos, sobre todo en los de Góngora» (Valle-Inclán 1910), Manuel Machado, con ironía y humor, iniciaba «Madrigal a una chica... que no entiende de madrigales» de Caprichos con un sonoro y desvergonzado «Gongorinamente, / te diré», y Rubén Darío en Cantos de vida y esperanza incluía su «Trébol» y sacaba a la palestra «la Galatea gongorina» en «Yo soy aquel que ayer no más decía». De este modo, quedaba abierto el camino para una recuperación total de la poesía más difícil del Píndaro andaluz.

A menudo se olvida que, al igual que en todo occidente, en España es el mismo ámbito de crisis y contradicciones el que forzosamente sustenta la sincrética creación artística del modernismo; éste es su contexto y su horizonte, el cual se reflejará en su obra artística, campo de batalla estético y emocional de esta serie de tensiones. Por ende, el modernismo también cuestionará y se distanciará de aquellos mismos presupuestos estéticos e ideológicos en los que parece sustentarse, según un proceso común a todo el arte occidental. Lo cierto es que estos fundamentos enumerados, que en el fin de siglo español germinaron en un conjunto de obras de gran calidad, sufrieron en la práctica un desgaste y agotamiento, una vulgarización manierista en sus procedimientos ya visible a finales de la primera década del siglo - y de la que sus mejores creadores fueron plenamente conscientes-, de los que vinieron a rescatarlos los autores posteriores, tras el abono que supusieron las vanguardias. En este sentido, sí hubo una reacción contra el modernismo imitativo, epigonal, esclerotizado y trillado. Hay un rechazo de esto, de todos los residuos decimonónicos, los retoricismos y los lugares comunes que pervivían en el modernismo, pero no de los orígenes y principios simbo-

${ }^{5}$ J. R. Jiménez, «Nocturnos», VIII, Arias tristes (1903); «Recuerdos sentimentales», XVII, ibid.; «Marinas sentimentales», VII, Poemas májicos y dolientes (1909); «La flauta y el arroyo», II, La soledad sonora (1911). 
listas básicos, ya enumerados, de Baudelaire a Mallarmé, que constantemente son reinterpretados, ni de los maestros modernistas que los llevaron a la práctica, los Machado, Juan Ramón o Unamuno ${ }^{6}$. Resulta bien significativo que Gerardo Diego incluyera a los cuatro a la cabeza de su Antología de 1932. Lo que sí hace la vanguardia y la joven literatura de los años veinte es, por un lado, aligerar el componente místico y neoplatónico que poseía parte del simbolismo -aunque el creacionismo, por ejemplo, actualiza parte de estos presupuestos según sus intereses-, y acentuar la mirada en sus procesos intelectuales, sintéticos, reflexivos y críticos (procesos que ya estaban en el modernismo: «Las emociones intelectuales [...] son las emociones contemporáneas. A mi entender la potencia emotiva del corazón se va substituyendo en nuestros días por el poder emocional del intelecto». No son palabras de ningún joven poeta de los años 20, sino de Gregorio Martínez Sierra en 1905 [Martínez Sierra 1905, pág. 25]). Y, por otra parte, exacerbar un vitalismo de base nietzscheana, estetificando al máximo el mundo exterior y sus objetos en una optimista glorificación. Pero resulta que incluso las vanguardias en España se nutrieron del simbolismo, puesto que en buena medida, supusieron una relectura de sus teorías, principalmente de Mallarmé, en el ultraísmo, como señaló repetidamente Cansinos-Asséns, y en el creacionismo: los planteamientos de Huidobro reproducen en parte las ideas mallarmeanas, e incluso diversos principios del romanticismo alemán de Schiller o Novalis, en una nueva poética trascendentalista e idealista, donde el poeta se autoconsagra como vate visionario y creador.

Toda la polémica de la poesía pura, tan típica de los años veinte, tiene una base simbolista, aunque de origen idealista romántico ${ }^{7}$. Valéry sigue sosteniendo la esencia inalcanzable de la poesía en el misterio, un ideal al que se tiende pero que no se alcanza. Todo la literatura de los años veinte sigue manteniendo esta visión de lo lírico como algo indefinible y huidizo. Bien significativas resultan, por ejemplo, las poéticas de la antologías de Diego de 1932 y 1934. La mayoría

Cf. J. R. Jiménez, «Prólogo al modernismo»: «Podríamos definirlo así: lo que cayó del modernismo fue la aristocracia falsa: las joyas materiales, la galantería literaria, la mujer vestida. Lo que quedó: lo aristocrático verdadero, la joya espiritual e ideal, el ánimo grande, la mujer desnuda. Cayó la aristocracia de salón. Quedó la aristocracia de intemperie», Y para recordar por qué he venido, ed. Javier Blasco, Valencia, Pre-Textos, 1990, pág. 99.

${ }^{7}$ «Como en la realidad no se puede encontrar ningún efecto estético puro (pues el hombre jamás puede sustraerse a la dependencia de sus fuerzas), la excelencia de una obra de arte puede consistir únicamente en su mayor aproximación a aquel ideal de pureza estética, y, con toda la libertad a que pueda elevarse, nos dejará siempre en una disposición especial y con una dirección propia»; éstas no son palabras de Mallarmé o Valéry, sino de Schiller, Cartas sobre la educación estética del hombre, carta XXII. 
tiene inequívocamente un origen y un lenguaje simbolista que exalta tanto el misterio y lo inefable de la creación poética como el papel del poeta; no sólo los autores modernistas, sino los más jóvenes; así, Moreno Villa: «El fenómeno poético es un estado de gracia»; Antonio Espina: «Poesía es lo puro indecible»; Domenchina: «El delirio poético -o profético- alcanza y resume lo inabarcable»; Salinas: «La poesía es una aventura hacia lo absoluto», una «fuerza latente y misteriosa»; Dámaso Alonso: «La Poesía es $[. .$.$] un fervor, un deseo íntimo y fuerte$ de unión con la gran entraña del mundo», «expresión» de una «realidad profunda», y «el poeta siente el deseo de la creación artística: fijar aquel momento suyo, hacerlo perenne»; Gerardo Diego: «La Poesía es la luminosa sombra divina del hombre»; Vicente Aleixandre: la poesía es «lo siempre inexplicable», «fuerza incalificable», «realidad suprasensible», «enigma», «oscura revelación»; o Luis Cernuda: la poesía es «misterioso dominio», «fugacísima luz entre tinieblas eternas» que «permanece escondida». Que a este arte de esencias se llegue a través de un gran esfuerzo intelectual, según recuerdan, por ejemplo, Domenchina o García Lorca, es una característica que ya estaba presente en el simbolismo, donde paradójicamente, conseguir en el lector un efecto de máxima sugestión y misterio es el resultado de cada vez más elaborados y medidos procedimientos técnicos en el cultivo de la forma (Diego 1992).

Pero, como ya he indicado, la modernidad en las primeras décadas del siglo XX no debe buscarse sólo en la aspiración a la autonomía pura de la imagen. Tan simbolista es el «puro» Mallarmé como el «impuro» Rimbaud. Precisamente, la línea impura de iconoclasta juego verbal desarrollada por Verlaine, Corbière o Laforgue -los dos últimos modelos para T. S. Eliot-, más otros poetas expresionistas como Jacob von Hoddis o Alfred Lichtenstein, y continuada por Jarry, Apollinaire, Cendrars, Salmon, Jacob, Éluard o Reverdy, muestra que la combinación de la ironía con el despojo retórico y grandilocuente, la mezcla de estilos, los sobreentendidos, la burla de sí mismo, el coloquialismo, el tono impertinente, travieso e inoportuno, los versos sincopados y la rima lúdica, el humor y la musicalidad popular, a la vez violento y sentimental, la sorpresa y lo subitáneo, la destrucción de las convenciones y del yo poético, el disparate gratuito, la quiebra repentina de las expectativas, las imágenes deliberadamente triviales o grotescas, la distorsión cómica y expresiva, el contraste y el conflicto humorístico, el tono naîf, la superposición simultánea de diversos elementos y la falta muchas veces de una estricta sucesión causal, sugiere otra línea de modernidad quizá peor rastreada en la poesía española, y en cuyos inicios se encontraron modernistas como Manuel Machado o Valle-Inclán, amén de otros menores, muchos de ellos pioneros del vanguardismo, y que luego, quintaesenciada, fue seguida en distintos grados por Ramón Gómez de la Serna, Adriano del Valle, Antonio Espina, 
Moreno Villa, Domenchina, Gerardo Diego, Alberti, García Lorca o Dámaso Alonso, entre otros (Alarcón Sierra 2000c, págs. 19-47; más ampliamente en Alarcón Sierra 1999b).

Es evidente que, en este tiempo, no siempre por querer ser más vanguardista se fue más moderno. O dicho de otra manera: vacunados ya contra la dogmática idea de una inexistente progresión lineal de la literatura, sabemos que la vanguardia a comienzos de siglo no supuso la única forma de modernidad. Hay que reexaminar a fondo la historia de los constantes entrecruzamientos de transición entre «modernismo» y «vanguardia», lo que nos llevará más de una sorpresa. La manera y la facilidad con que muchos poetas de formación e iniciación «modernista» -incluyendo la mayoría de los del «27》- pasaron con total fluidez a trabajar en postulados más «avanzados» 0 «vanguardistas» muestra la ausencia de una incompatibilidad frontal o traumática, un desarrollo de expectativas que el simbolismo estaba posibilitando desde sus postulados más modernos.

\section{BIBLIOGRAFÍA CITADA}

Alarcón SierRa, R., 1997. «Manuel Machado y Wagner (con Schopenhauer y Nietzsche): la música, el mito y la consagración del instante», Ínsula, 608-609, págs. 8-11.

- 1998. «La 'generación del 98' y El hombre que fue jueves», InterLetras. Revista de Crítica y Literatura en Lengua Española, 4 (http://fyl.unizar.es/gcorona/interlet.htm).

- 1999a. «La ciudad y el domingo; el poeta y la muchedumbre (de Baudelaire a Manuel Machado)», Anales de la Literatura Española Contemporánea, 24, 1-2, págs. 35-64.

- 1999b. Entre el modernismo y la modernidad: la poesía de Manuel Machado («Alma»y «Caprichos»), Sevilla, Diputación Provincial de Sevilla.

- 2000a. «Contra Manuel Machado: la deconstrucción de su no-identidad en El mal poema», Hispanic Review, 68, 2, págs. 161-181.

- 2000b. «La herencia modernista en la poesía de Federico García Lorca», en A. Soria Olmedo, M. J. Sánchez Montes y J. Varo Zafra (coords.), Federico García Lorca, clásico moderno (1898-1998). Congreso Internacional, Granada, Diputación de Granada, págs. 451-483.

- 2000c. «iPura farsa!. La genealogía moderna del arte como juego y lo lúdico en la poesía de Manuel Machado (con cine y toros)», en Gabriele Morelli 
(ed.), LUDUS. Cine, arte y deporte en la literatura española de vanguardia, Valencia, Pre-Textos.

- 2001. «Las prosas dispersas de Antonio Machado (1893-1936)», en A. Machado, Prosas dispersas (1893-1936) ed. J. Doménech, Madrid, Páginas de Espuma, págs. 15-97.

Alonso, Dámaso [1948] 1958. «Una generación poética (1920-1936)», en Poetas españoles contemporáneos, Madrid, Gredos, págs. 167-192.

Balakian, Anna, 1969. El movimiento simbolista. Juicio crítico, Madrid, Guadarrama.

- (ed.), 1982. The Symbolist Movement in the Literature of European Languages, Budapest, Akadémiai Kiadó.

Boner, J. M., 1995. Diccionario de la vanguardia en España (1907-1936), Madrid, Alianza.

BRAUDEL, Fernand, [1958] 1968. «La larga duración», en La historia y las ciencias sociales, Madrid, Alianza, págs. 60-106.

BUCKLEY, R. y CRISPIN J. (eds.), 1973. Los vanguardistas españoles (1925-1935), Madrid, Alianza.

Cano BallestA, J., 1972. La poesía española entre pureza y revolución (1930-1936), Madrid, Gredos.

- 1996. La poesía española entre pureza y revolución (1920-1936), Madrid, Siglo XXI.

CARDWEll, R., 1997. «Alma, de Manuel Machado, iprimer libro de las vanguardias?», Insula, 608-609, págs. 6-8; monogr. «'Gloria... ¡la que me deben!'. Manuel Machado (1947-1997)», coord. R. Sierra Alarcón.

CLARÍN [Leopoldo Alas], 1892. Ensayos y Revistas (1888-1892), Madrid, Fernández y Lasanta.

- 1894. Palique, Madrid, Victoriano Suárez.

DeBICKI, Andrew, 1997. Historia de la poesía española del siglo XX. De la modernidad hasta el presente, Madrid, Gredos.

Díaz GaYo, Félix, 1902. «As you like it», Gente vieja, 19. 
Diego, Gerardo, 1919. «Posibilidades creacionistas», Cervantes, octubre, págs. 23-28.

- 1923. «Juan Ramón Jiménez: Segunda antología poética», Revista de Occidente, I, págs. 364-368.

- 1926. «En torno a Debussy», Revista de Occidente, XIV, págs. 394-401.

- 1927. «Devoción y meditación de Juan Gris», Revista de Occidente, XVI, págs. 160-180.

- 1992. Poesía española contemporánea. Antología (1932-1934). Ed. A. Soria Olmedo, Madrid, Taurus.

DöHL, Reinhard, 1967. Das litterarische Werk Hans Arps 1903-1930, Stuttgart, Metzler.

Foster, J. B. 1981. Heirs to Dionysus: A Nietzschean Current in Literary Modernism, Princeton, NJ, UP.

FRAY CANDIL [Emilio Bobadilla], 1903, «Desde mi celda», Alma Española, 8 de noviembre.

GeIST, Anthony L., 1980. La poética de la generación del 27 y las revistas literarias: de la vanguardia al compromiso (1918-1936), Barcelona, Labor.

GuILLÉN, Claudio, 1985. «Las configuraciones históricas: historiología», en Entre lo uno y lo diverso. Introducción a la literatura comparada, Barcelona, Crítica, págs. 362-431.

- 1989. «Cambio literario y múltiples duraciones», en Teorías de la historia literaria, Madrid, Espasa Calpe («Austral»), págs. 249-281.

GullLén, Jorge, [1924] 1980. «Nuevas Canciones», La Libertad, 30 de mayo de 1924; en K. M. Sibbald (ed.), Hacia «Cántico». Escritos de los años 20, Barcelona, Ariel.

Hertz, D. M., 1987. The Tuning of the Word: Music-Literary Poetics of the Symbolist Movement, Carbondale, Southern Illinois UP.

HuRET, Jules, 1891. Enquête sur l'évolution littéraire. París, Charpentier.

JiMÉnEZ, Juan Ramón, [1903] 1969. Reseña de Soledades; recogida en F. Garfias (ed.), Libros de prosa, Madrid, Aguilar, I. 
- 1936. «Recuerdo al primer Villaespesa. 1899-1901», El Sol, 10 de mayo.

- 1999. El modernismo. Apuntes de curso (1953), ed. Jorge Urrutia, Madrid, Visor.

Machado, Manuel, 1901. «Impresiones literarias. En casa de Villaespesa», $E l$ País, 30 de enero.

MAINER, José-Carlos, 1981. «De historiografía literaria española: el fundamento liberal», en AA. VV., Estudios de historia de España. Homenaje a Manuel Tuñón de Lara, Madrid, UIMP, vol. II, págs. 439-472.

- 1989. Historia, literatura y sociedad, Madrid, Espasa Calpe.

- 1994, «La invención de la literatura española», en J. M. Enguita y J.-C. Mainer (eds.), Literaturas regionales en España. Historia y crítica, Zaragoza, Institución «Fernando el Católico», págs. 23-45.

Martínez Sierra, G., 1905. Motivos, París, Garnier Hermanos.

Salaün, Serge, 1991. «Búsqueda de modernidad y búsqueda formal», en S. Salaün y C. Serrano (eds.), 1900 en España, Madrid, Espasa Calpe, 1991.

SALINAS, Pedro, [1940] 1970. «El signo de la literatura española del siglo XX», en Literatura Españolà Siglo XX, Madrid, Alianza.

SteINER, George, 1980. Después de Babel. Aspectos del lenguaje y la traducción, México, FCE.

VAlle-INCLÁN, R. del, 1910. «El modernismo», La Nación (Buenos Aires), 6 de julio.

WILsON, Edmund, 1977. El castillo de Axel. Estudios sobre literatura imaginativa de 1870-1930, Madrid, Cupsa Editorial. 